\title{
Radiological scales predicting delayed cerebral ischemia in subarachnoid hemorrhage: systematic review and meta-analysis
}

\author{
Wessel E. van der Steen ${ }^{1,2} \cdot$ Eva L. Leemans ${ }^{1,3} \cdot$ René van den Berg ${ }^{3} \cdot$ Yvo B. W. E. M. Roos $^{2} \cdot$ Henk A. Marquering ${ }^{1,3}$ (D) \\ Dagmar Verbaan $^{4}$. Charles B. L. M. Majoie ${ }^{3}$
}

Received: 6 December 2018 / Accepted: 3 January 2019 / Published online: 28 January 2019

(C) The Author(s) 2019

\begin{abstract}
Purpose Delayed cerebral ischemia (DCI) is a severe complication of aneurysmal subarachnoid hemorrhage (aSAH). The extent of subarachnoid blood is a strong predictor of DCI and is frequently estimated with the Fisher scale, modified Fisher scale, or Hijdra sum score. It is unclear which scale has the strongest association with clinical DCI. To evaluate this, we performed a systematic review of the literature.

Methods We performed a MEDLINE and EMBASE search from 1980 to 20th of June 2017. Radiological grade and occurrence of clinical DCI were extracted along with odds ratios (ORs) for DCI. When possible, pooled ORs with $95 \%$ confidence intervals were calculated per grade increase on the radiological scale.

Results Fifty-three studies were included. The Fisher scale was significantly associated with DCI in $62 \%$ of the studies compared to $88-100 \%$ for the other scales. In studies using the Fisher scale, Fisher 3 had the strongest association with DCI (pooled OR 3.21 (1.87-5.49)). In studies using the modified Fisher score, DCI occurred most frequently (42\%) in modified Fisher 4. No pooled OR could be calculated for the other scales.

Conclusion The Fisher scale, modified Fisher scale, and Hijdra sum score are all associated with clinical DCI. The risk of DCI, however, does not increase with increasing Fisher grade as opposed to the modified Fisher scale. Furthermore, the modified Fisher scale was more commonly significantly associated with DCI than the Fisher scale, which may advocate using the modified Fisher in future SAH-related studies.
\end{abstract}

Keywords Delayed cerebral ischemia $\cdot$ Radiological scale $\cdot$ Subarachnoid hemorrhage $\cdot$ Systematic review

Electronic supplementary material The online version of this article (https://doi.org/10.1007/s00234-019-02161-9) contains supplementary material, which is available to authorized users.

Henk A. Marquering

h.a.marquering@amc.uva.nl

1 Department of Biomedical Engineering \& Physics, Amsterdam UMC, University of Amsterdam, Room L0-106, Academic Medical Center, Meibergdreef 9, 1105 AZ Amsterdam, The Netherlands

2 Department of Neurology, Amsterdam UMC, University of Amsterdam, Amsterdam, The Netherlands

3 Department of Radiology and Nuclear Medicine, Amsterdam UMC, University of Amsterdam, Amsterdam, The Netherlands

4 Neurosurgical Center Amsterdam, Amsterdam UMC, University of Amsterdam, Amsterdam, The Netherlands

\section{Introduction}

Delayed cerebral ischemia (DCI) is one of the most severe complications of aneurysmal subarachnoid hemorrhage (aSAH) and occurs in approximately $30 \%$ of the patients [1, 2]. The extent of subarachnoid blood on admission computed tomography (CT) scan is one of the strongest predictors of DCI [3-5]. However, it is not clear which radiological grading scale has the strongest association with DCI. Over the years, several radiological grading scales have been introduced [6]. The first scale was introduced by Fisher et al. in 1980 [7]. This four-grade scale scores the amount of blood in the cisterns as absent (grade 1), diffuse thin $(<1 \mathrm{~mm})$ (grade 2), thick (> $1 \mathrm{~mm}$ ) (grade 3), or thin amount of blood in the cisterns with presence of intraventricular (IVH) or intraparenchymal (IPH) hemorrhage (grade 4). Later, an adjusted version of the Fisher scale was published: the modified Fisher scale $[8,9]$. This scale introduced a separate grade for patients with both a thick 
layer of blood in the cisterns and presence of IVH. An alternative, more extensive but more time consuming scale is the Hijdra sum score, which grades the amount of blood in each cistern separately [4].

Several studies have assessed the association of these radiological grading scales with the occurrence of DCI [4, 7-10]. However, prior to 2010, DCI has not been unambiguously defined [11]. When the Fisher scale was introduced, DCI was believed to be caused by vasospasm and thus angiographic vasospasm was frequently used as end point. Presently, DCI is regarded a multifactorial process, which results in neurological deterioration [12]. The question remains how well the grading scales are associated with this current clinical definition of DCI [11]. We aimed to perform a systematic review to assess the associations of the Fisher scale, the modified Fisher scale, and Hijdra sum score with clinical DCI.

\section{Methods}

\section{Search strategy}

We performed this review according to the PRISMA statement [13]. We performed a MEDLINE and EMBASE search for records published between 1980 and 20th of June 2017. The search terms "subarachnoid hemorrhage," "Fisher," "Hijdra," "score/grade," and "computed tomography," were used. Furthermore, as numerous terms for DCI are used in literature, we included the following terms for DCI: "delayed cerebral ischemia," "delayed cerebral infarction" "delayed cerebral deficit," "symptomatic vasospasm," "cerebral vasospasm," "delayed ischemic neurological deficit," "delayed ischemic neurological deterioration," and "cerebral infarction." For the full search strategy, please see the Online supplemental text 1 .

\section{Study selection}

Studies that met the following criteria were included: (1) SAH proven on CT images; (2) aneurysm shown on an angiographic study; (3) amount of blood graded on admission CT by either the Fisher scale, modified Fisher scale, or Hijdra sum score; (4) outcome was clinical DCI, defined by at least the occurrence of new focal neurological signs and/or a decrease in consciousness, with or without angiographic vasospasm or new infarct on follow-up CT scan; and (5) an association between the radiological grade and DCI was reported. In case two studies used (part of) the same dataset and assessed the same radiological scale, the study with the largest patient population was included. We excluded studies that included mainly patients younger than 18 years, studies in another language than English, Dutch or German, case reports, reviews, and conference abstracts. One reviewer (W.S.) screened all titles and abstracts for eligibility for full text review. Two reviewers (W.S. and E.L.) independently reviewed all full texts for inclusion in the review. The final decision on inclusion was made through consensus between the two reviewers.

\section{Data extraction}

Data extraction from the included studies was independently performed by two reviewers (W.S. and E.L.) using a standardized form. Crude data on radiological grade and occurrence of DCI were extracted along with, if available, the odds ratios (OR) for the occurrence of DCI. If the ORs were not available, ORs for DCI were calculated from the crude data in case these data were provided. Furthermore, we extracted whether an association between the radiological grade and DCI was found, both in univariable and multivariable analysis. Other collected variables were age, sex, and treatment modality (clipping or coiling). Differences in extracted data were evaluated by the two reviewers and resolved by consensus.

\section{Quality assessment}

Risk of bias was assessed by two reviewers independently (W.S. and D.V.) using the Newcastle-Ottawa quality assessment (NOS) scale for cohort and case control studies and the Cochrane Handbook risk of bias tool for randomized controlled trials $[13,14]$. Cohort studies could be awarded a maximum of 9 points. Randomized controlled trials could be awarded a maximum of 7 points. In case an item of the scale was inapplicable, a lower maximum of points could be awarded. Points could be awarded for selection, comparability, and outcome assessment. The study population was considered unselected if no selection was made based on clinical condition, co-morbidities, and treatment of the aneurysm. A follow-up period for DCI of at least 2 weeks was considered sufficient. Follow-up was considered adequate if a DCI status (DCI or no DCI) was available for at least $80 \%$ of the included patients. Differences in risk of bias assessment between reviewers were resolved through consensus.

\section{Statistical analyses}

Mean age (standard deviation), percentage male sex, number of patients in each radiological grade, and occurrence of DCI per radiological grade were calculated using data from all studies that provided the crude data.

Pooled ORs with $95 \%$ confidence intervals for DCI were calculated for the radiological scales, both dichotomized and per grade on the radiological scale using Mantel Haenszel statistics. The Fisher and modified Fisher scale were dichotomized at grade 2 and the Hijdra sum score at grade 23. Pooled ORs were only calculated in case multiple studies reported crude data on patients for all grades of the radiological scale. 
The risk for DCI was compared between all grades of each radiological scale using each grade as reference in separate analyses. A random effects model was applied to calculate the pooled ORs. Statistical heterogeneity of the studies included in the meta-analysis was assessed using the $I^{2}$ statistic. An $I^{2}$ of $0-30 \%$ was considered no relevant heterogeneity, 30 $50 \%$ moderate heterogeneity, $50-75 \%$ substantial heterogeneity, and $75-100 \%$ considerable heterogeneity [14]. The possibility of publication bias was assessed by plotting the effect of the studies included in the meta-analysis by the inverse of its standard error, thus creating a funnel plot. Funnel plots were visually assessed for asymmetry which could indicate a publication bias.

A sensitivity analysis was performed comparing studies that used clinical signs only to diagnose DCI to studies that used both a radiological and clinical definition.

Analyses were performed using SPSS version 24.0.0.1 (IBM SPSS Statistics for Windows, Armonk, NY: IBM Corp) and Review Manager 5.3.5 (RevMan, Copenhagen: The Nordic Cochrane Centre, The Cochrane Collaboration, 2014).

\section{Results}

\section{Study characteristics}

The MEDLINE and EMBASE search yielded, after removal of duplicates, 6766 records. After screening of titles and abstracts, 274 full-text articles were screened for inclusion. Of the full-text articles, 221 studies were excluded. The main reasons for exclusion were the following: amount of blood not assessed with the Fisher, modified Fisher, or Hijdra sum score $(n=38)$, clinical DCI not one of the assessed outcomes $(n=114)$, and no association between amount of blood and DCI could be determined ( $n=51)$ (Fig. 1$)$.

Fifty-three studies were included, including 13,612 patients with a mean age of 52.4 (SD 3.5) years of which $66 \%$ was female. Table 1 shows the study characteristics of the included studies.

In total 50 cohort studies, one case-control study and two randomized controlled trials were included. DCI occurred in $29 \%$ of the patients. In 28 studies (53\%), the diagnosis of DCI was based on clinical signs in combination with angiographic vasospasm. In the remaining 25 studies (47\%), the diagnosis of DCI was based on clinical signs only. No sufficient uniform data could be extracted on treatment modality.

None of the included studies received the maximum score on the quality assessment scale. The mean amount of awarded points was 5.2 (SD 1.6). Items that were most often rewarded points for were comparability of the cohorts $(82 \%)$ and assessment of DCI $(98 \%)$. However, most studies did not use an unselected study cohort (69\%), showed no demonstration that

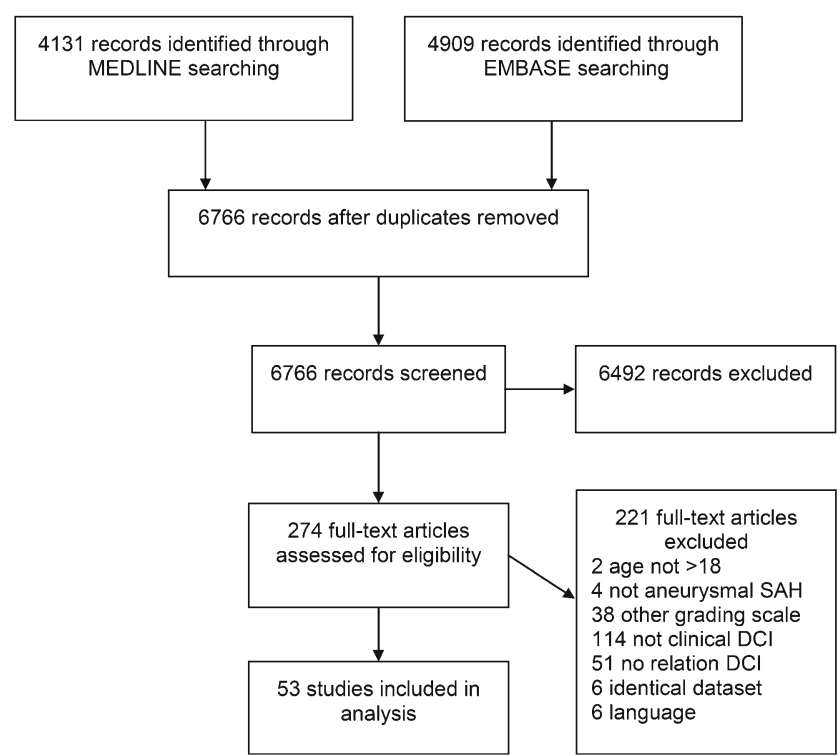

Fig. 1 PRISMA flowchart

DCI was not present at baseline (93\%), and did not use a follow-up period of a least 2 weeks (56\%) (Table 1).

\section{Fisher scale}

The Fisher scale was used in 42 studies (79\%), including 10,429 patients. Of these 42 studies, 25 studies ( 5701 patients) reported patients for all Fisher grades and provided detailed data on the number of patients in each grade. A mean percentage of 6 (SD 6; range 0-23) was classified as Fisher 1, 18 (SD 9; range 0-37) as Fisher 2, 51 (SD 17; range 17-83) as Fisher 3 , and 27 (SD 14; range 5-73) as Fisher 4. The distribution of patients in each Fisher grade in these studies is shown in Online supplemental Fig. 1.

Crude data on the number of patients that developed DCI in each Fisher grade was extracted from 25 studies (7222 patients), a mean percentage of 13 (SD 7; range 0-29) of patients with Fisher 1, 24 (SD 10; range 0-43) of patients with Fisher 2, 37 (SD 11; range 23-96) of patients with Fisher 3, and 30 (SD 13; range 0-70) of patients with Fisher 4 developed DCI.

The Fisher grade was significantly associated with DCI in 23 of 39 studies $(62 \%)$ that performed an univariable analysis. Of the 29 studies that performed a multivariable analysis, the Fisher scale was independently associated with DCI in 16 studies $(55 \%)$.

Of the 25 studies (5701 patients) that reported patients for all Fisher grades, 14 studies (4413 patients) provided data on occurrence of DCI that allowed to calculate a pooled OR by dichotomized Fisher grade and 10 studies (3939 patients) to calculate a pooled OR per Fisher grade. The pooled OR $(95 \%$ CI) for DCI was 2.22 (1.54-3.19) for Fisher 3 to 4 compared to Fisher 1 to 2. Compared to Fisher 1, the pooled OR (95\% CI) for DCI was 1.53 (1.01-2.32) for Fisher 2 (Fig. 2a), 3.21 
Table 1 Study characteristics

\begin{tabular}{|c|c|c|c|c|c|c|c|}
\hline Author & Study type & Radiological scale & Patients & Mean age $( \pm \mathrm{SD})$ & Male sex $(\%)$ & DCI $(\%)$ & Study quality \\
\hline Fisher et al. [7] & $\mathrm{Pc}$ & Fisher & 47 & $48(\mathrm{n} / \mathrm{a})$ & 30 & 49 & 2 of $9^{*}$ \\
\hline Allen et al. [15] & RCT & Fisher & 121 & $46(n / a)$ & 34 & 24 & 1 of $7 \dagger$ \\
\hline Adams et al. [16] & $\mathrm{Rc}$ & Fisher & 934 & $\mathrm{n} / \mathrm{a}$ & $\mathrm{n} / \mathrm{a}$ & 32 & 8 of $9^{*}$ \\
\hline Grosset et al. [17] & $\mathrm{Pc}$ & Fisher & 121 & $47(2.6)$ & $\mathrm{n} / \mathrm{a}$ & 39 & 2 of $9^{*}$ \\
\hline Rabb et al. [18] & $\mathrm{Rc}$ & Fisher & 178 & $45(\mathrm{n} / \mathrm{a})$ & 40 & 21 & 4 of $9^{*}$ \\
\hline Lasner et al. [19] & $\mathrm{Pc}$ & Fisher & 70 & $49.8(13.6)$ & 37 & 29 & 5 of $9 *$ \\
\hline Murayama et al. [20] & $\mathrm{Rc}$ & Fisher & 69 & $52(\mathrm{n} / \mathrm{a})$ & 26 & 23 & 4 of $7^{*}$ \\
\hline Charpentier et al. [21] & $\mathrm{Rc}$ & Fisher & 244 & $\mathrm{n} / \mathrm{a}$ & 40 & 19 & 7 of $9^{*}$ \\
\hline Juvela et al. [22] & $\mathrm{Pc}$ & Fisher & 70 & $46(n / a)$ & 51 & 41 & 6 of $9^{*}$ \\
\hline McGirt et al. [23] & $\mathrm{Rc}$ & Fisher & 223 & $53(15)$ & 44 & 45 & 6 of $9 *$ \\
\hline Dehdashti et al. [24] & $\mathrm{Pc}$ & Fisher & 98 & $50(\mathrm{n} / \mathrm{a})$ & 36 & 22 & 3 of $9^{*}$ \\
\hline Klimo et al. [25] & $\mathrm{Pc}$ & Fisher & 167 & $53(\mathrm{n} / \mathrm{a})$ & $\mathrm{n} / \mathrm{a}$ & 35 & 5 of $8^{*}$ \\
\hline Singhal et al. [26] & $\mathrm{Pc}$ & Fisher & 514 & $55(14)$ & 29 & 29 & 7 of $9^{*}$ \\
\hline Reilly et al. [27] & $\mathrm{Rc}$ & Fisher & 75 & $51(14)$ & 27 & 35 & 3 of $8^{*}$ \\
\hline Hoh et al. [28] & $\mathrm{Pc}$ & Fisher & 515 & $54(14)$ & 29 & 29 & 7 of $9^{*}$ \\
\hline Hirashima et al. [29] & $\mathrm{Rc}$ & Fisher & 145 & $59.3(13.3)$ & 30 & 28 & 6 of $9 *$ \\
\hline Smith et al. [30] & $\mathrm{Rc}$ & Fisher & 134 & $54(\mathrm{n} / \mathrm{a})$ & 30 & 21 & 8 of $9^{*}$ \\
\hline Oertel et al. [31] & $\mathrm{Pc}$ & Fisher & 51 & $52(11)$ & 39 & 51 & 5 of $9 *$ \\
\hline Frontera et al. [9] & $\mathrm{Rc}$ & Fisher, Modified Fisher & 1355 & $\mathrm{n} / \mathrm{a}$ & $\mathrm{n} / \mathrm{a}$ & 33 & 7 of $9 *$ \\
\hline McGirt et al. [32] & $\mathrm{Rc}$ & Fisher & 115 & $54(14)$ & 32 & 43 & 3 of $8^{*}$ \\
\hline Oh et al. [33] & $\mathrm{Rc}$ & Fisher & 158 & $51(10)$ & 38 & 29 & 4 of $9^{*}$ \\
\hline Krishnamurthy et al. [34] & $\mathrm{Rc}$ & Fisher & 320 & $53.5(14.6)$ & 31 & 43 & 6 of $9^{*}$ \\
\hline Gonzalez et al. [35] & $\mathrm{Rc}$ & Fisher & 68 & $58.0(13.2)$ & 40 & 27 & 5 of $8^{*}$ \\
\hline Dhar et al. [36] & $\mathrm{Pc}$ & Fisher & 276 & $55.9(13.5)$ & 36 & 24 & 7 of $9^{*}$ \\
\hline Starke et al. [37] & $\mathrm{Pc}$ & Fisher & 77 & $54(12)$ & 36 & 30 & 6 of $8^{*}$ \\
\hline Kramer et al. [38] & $\mathrm{Rc}$ & Fisher, Modified Fisher & 237 & $53(\mathrm{n} / \mathrm{a})$ & 32 & 26 & 6 of $9^{*}$ \\
\hline Rivero-Arias et al. [39] & $\mathrm{Rc}$ & Fisher & 1644 & $52(\mathrm{n} / \mathrm{a})$ & 36 & 25 & 6 of $9^{*}$ \\
\hline Dumont et al. [40] & $\mathrm{Rc}$ & Modified Fisher & 113 & $53.8(1.1)$ & 37 & 37 & 4 of $9 *$ \\
\hline Kramer et al. [41] & $\mathrm{Rc}$ & Hijdra & 138 & $\mathrm{n} / \mathrm{a}$ & $\mathrm{n} / \mathrm{a}$ & 28 & 6 of $9^{*}$ \\
\hline Kasius et al. [42] & $\mathrm{Rc}$ & Hijdra & 91 & $54(13)$ & 25 & 36 & 7 of $8^{*}$ \\
\hline Yousef et al. [43] & $\mathrm{Rc}$ & Fisher & 149 & $53.8(10.5)$ & 31 & 48 & 6 of $8^{*}$ \\
\hline Oliveira et al. [44] & $\mathrm{Pc}$ & Fisher, modifed Fisher & 24 & $54(11)$ & 21 & 42 & 6 of $9^{*}$ \\
\hline Ibrahim et al. [45] & $\mathrm{Pc}$ & Hijdra & 413 & $\mathrm{n} / \mathrm{a}$ & 29 & $\mathrm{n} / \mathrm{a}$ & 4 of $8^{*}$ \\
\hline Al-Tamimi et al. [46] & RCT & Modified Fisher & 210 & $51(2.5)$ & 26 & 28 & 5 of $7 \dagger$ \\
\hline Zhu et al. [47] & $\mathrm{Cc}$ & Modified Fisher & 303 & $43.9(12.4)$ & 43 & 43 & 5 of $9 *$ \\
\hline Wilson et al. [48] & $\mathrm{Rc}$ & Fisher & 218 & $54(12)$ & 26 & 21 & 4 of $9 *$ \\
\hline de Rooij et al. [49] & $\mathrm{Pc}$ & Modified Fisher, Hijdra & 255 & $56(\mathrm{n} / \mathrm{a})$ & 27 & 22 & 6 of $9 *$ \\
\hline Ohnishi et al. [50] & $\mathrm{Pc}$ & Fisher & 95 & $62.1(\mathrm{n} / \mathrm{a})$ & 44 & 23 & 5 of $9 *$ \\
\hline Karamchandani et al. [51] & $\mathrm{Rc}$ & Modified Fisher & 259 & $55(13)$ & 26 & 36 & 6 of $8^{*}$ \\
\hline Romero et al. [52] & $\mathrm{Pc}$ & Fisher & 100 & $48(n / a)$ & 56 & $\mathrm{n} / \mathrm{a}$ & 4 of $9^{*}$ \\
\hline Yousef et al. [53] & $\mathrm{Rc}$ & Fisher & 164 & $54(\mathrm{n} / \mathrm{a})$ & 28 & 57 & 6 of $8^{*}$ \\
\hline de Oliveira Manoel et al. [54] & $\mathrm{Pc}$ & Modified Fisher & 693 & $53(12)$ & 31 & 22 & 4 of $8^{*}$ \\
\hline Calviere et al. [55] & $\mathrm{Pc}$ & Fisher & 30 & $45(12)$ & 37 & 20 & 5 of $9 *$ \\
\hline Dhandapani et al. [56] & $\mathrm{Pc}$ & Fisher & 75 & $49(\mathrm{n} / \mathrm{a})$ & 52 & 29 & 4 of $9 *$ \\
\hline Rodriguez-Régent et al. [57] & $\mathrm{Pc}$ & Fisher & 47 & $50(\mathrm{n} / \mathrm{a})$ & 30 & 21 & 7 of $9 *$ \\
\hline Malinova et al. [58] & $\mathrm{Pc}$ & Fisher & 753 & $53(14)$ & 34 & 11 & 6 of $9 *$ \\
\hline Kozak et al. [59] & $\mathrm{Rc}$ & Fisher & 457 & $47.2(11)$ & 41 & 23 & 7 of $9 *$ \\
\hline Behrouz et al. [60] & $\mathrm{Rc}$ & Fisher & 135 & $43(15)$ & 41 & 24 & 5 of $8^{*}$ \\
\hline Mijiti et al. [61] & $\mathrm{Rc}$ & Modified Fisher & 343 & $\mathrm{n} / \mathrm{a}$ & 39 & 29 & 7 of $9^{*}$ \\
\hline
\end{tabular}


Table 1 (continued)

\begin{tabular}{|c|c|c|c|c|c|c|c|}
\hline Author & Study type & Radiological scale & Patients & Mean age $( \pm \mathrm{SD})$ & Male sex $(\%)$ & DCI $(\%)$ & Study quality \\
\hline Aldakkan et al. [62] & $\mathrm{Pc}$ & Fisher & 191 & $51(13)$ & 15 & 41 & 5 of $9^{*}$ \\
\hline Oda et al. [63] & $\mathrm{Rc}$ & Fisher, Hijdra & 151 & $61(14)$ & 30 & 23 & 5 of $8^{*}$ \\
\hline Griessenauer et al. [64] & $\mathrm{Pc}$ & Fisher, Modified Fisher, Hijdra & 149 & $55(13)$ & 24 & 23 & 6 of $9^{*}$ \\
\hline Rostami et al. [65] & $\mathrm{Pc}$ & Fisher & 30 & $58.9(\mathrm{n} / \mathrm{a})$ & 17 & 30 & 3 of $7 *$ \\
\hline
\end{tabular}

$P c$ prospective cohort, $R C T$ randomized controlled trial, $R c$ retrospective cohort, $C c$ case-control study, $n / a$ not available

*Scored on the NOS scale

$†$ Scored on the Cochrane Handbook risk of bias tool for randomized controlled trials scale

(1.87-5.49) for Fisher 3 (Fig. Fig. 2b), and 2.21 (1.49-3.28) for Fisher 4 (Fig. Fig. 2c), respectively. Patients with Fisher 4 had a significantly lower risk of DCI compared to patients with Fisher 3 (OR (95\% CI) 0.60 (0.37-0.97)) (Table 2).

There was no relevant statistical heterogeneity between the studies: the $I^{2}$ ranged between 0 and 20\%. Visual inspection of the funnel plot showed a symmetrical distribution of the study effects (Online supplemental Fig. 2).

\section{Modified Fisher scale}

The modified Fisher scale was used in 11 studies (21\%), including 3941 patients. Seven studies (2476 patients) included patients for all modified Fisher grades and provided data on the number of patients in each grade (Online supplemental Fig. 1). The majority of the studies grouped modified Fisher 0 and 1 together. A mean percentage of 20 (SD 4; range 11-29) was classified as modified Fisher 0-1, 11 (SD 4; range 0-20) as modified Fisher 2, 30 (SD 7; range 14-46) as modified Fisher 3, and 39 (SD 10; range 34-61) as modified Fisher 4.

Crude data on the number of patients that developed DCI in each modified Fisher grade was extracted from 5 studies (2085 patients). A mean percentage of 21 (SD 7; range 524) of patients with modified Fisher 0-1, 26 (SD 9; range 033 ) of patients with modified Fisher 2, 30 (SD 9; range 5-36) of patients with modified Fisher 3, and 42 (SD 9; range 3483 ) of patients with modified Fisher 4 developed DCI.

The modified Fisher grade was significantly associated with DCI in 7 of $8(88 \%)$ of studies that performed a univariable analysis and in 8 of $9(89 \%)$ studies that performed a multivariable analysis.

Of the 5 studies that reported patients for all modified Fisher grades, 4 (1959 patients) provided data on occurrence of DCI that allowed to calculate a pooled OR by dichotomized modified Fisher grade. The pooled OR (95\% CI) for DCI was 2.31 (1.40-3.81) for modified Fisher 3-4 compared to modified Fisher $0-2$. No pooled OR per grade increase on the modified Fisher was calculated; as of three studies (1616 patients) that provided data for the occurrence of DCI in all modified Fisher grades, one study included $84 \%$ of the patients.

\section{Hijdra sum score}

The Hijdra sum score was used in 6 studies (11\%), including 1197 patients. Mean Hijdra score in 4 studies (1048 patients) was 19 (SD 2; range 17-23). In two studies (289 patients) that reported the mean Hijdra score stratified by occurrence of DCI, mean Hijdra score was 24 (SD 2; range 22-26) in patients with DCI and 14 (SD 1; range 15-15) in patients without DCI.

The Hijdra score was significantly associated with DCI in both studies that performed univariable analysis and in all four studies that performed multivariable analysis. None of the studies provided crude data that allowed for calculating a pooled OR.

\section{Sensitivity analysis}

A sensitivity analysis was performed in the meta-analysis of the Fisher scale. Four studies (3254 patients) diagnosed DCI using clinical signs only, whereas the other 6 studies (673 patients) combined clinical signs with angiographic vasospasm. In studies that used clinical signs only to diagnose DCI, both Fisher 3 (OR (95\%CI) 2.48 (1.703.60)) and Fisher 4 (OR (95\%CI) 2.11 (1.23-3.61)) were significantly associated with DCI. In studies combining clinical signs with angiographic vasospasm to diagnose DCI, Fisher 3 (OR (95\%CI) 8.79 (2.08-37.12)) was significantly associated with DCI (Online supplemental Table 1).

\section{Discussion}

In this systematic review, pooled analysis of the Fisher scale showed that all Fisher grades have an increased risk of clinical DCI compared to Fisher 1, with Fisher 3 patients having the highest risk of DCI. Nevertheless, the highest rate of DCI was seen in patients with modified 
a

Fisher 2 Fisher $1 \quad$ Odds Ratio

Odds Ratio

Study or Subgroup Events Total Events Total Weight M-H, Random, 95\% Cl Year

\begin{tabular}{llllllll}
\hline Fisher et al. & 0 & 7 & 0 & 11 & Not estimable 1980
\end{tabular}

$\begin{array}{llllllll}\text { Grosset et al. } & 12 & 33 & 2 & 7 & 5.5 \% & 1.43[0.24,8.53] & 1993\end{array}$

Murayama et al.

Dehdashti et al.

Smith et al.

Frontera et al.

Rivero-arias et al.

Kramer et al.

Oliveira et al.

Wilson et al.

Total $(95 \% \mathrm{Cl})$

0

$\begin{array}{ll}0 & 10 \\ 3 & 24\end{array}$

$8 \begin{array}{ll}34 \\ 3 & 34\end{array}$

$\begin{array}{ll}37 & 148\end{array}$

$51 \quad 273$

$\begin{array}{rr}2 & 30 \\ 1 & 5\end{array}$

Not estimable 1997

$3.09[0.15,65.97] 2003$

$4.17[0.21,81.96] 2005$

$1.23[0.68,2.23] 2006$

$1.88[0.94,3.77] 2009$

$1.14[0.05,26.71] 2009$

$1.00[0.02,40.28] 2011$

$3.26[0.14,77.84] 2012$

Total events

577

$1.53[1.01,2.32]$

Heterogeneity: $\mathrm{Tau}^{2}=0.00 ; \mathrm{Chi}^{2}=1.81, \mathrm{df}=7(\mathrm{P}=0.97) ; \mathrm{I}^{2}=0 \%$

Test for overall effect: $Z=1.98(P=0.05)$

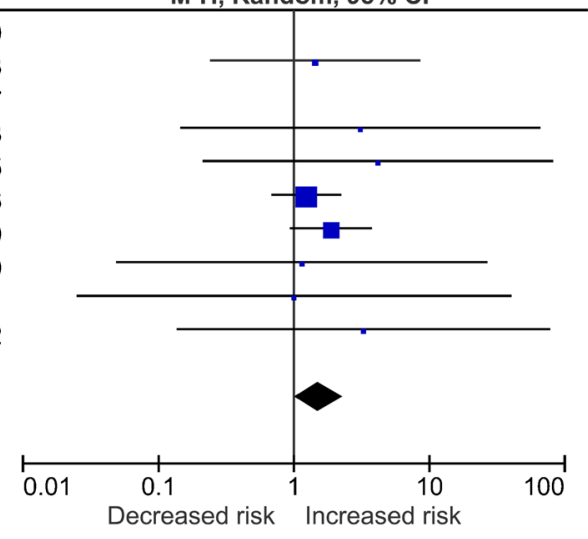

b

Fisher 3 Fisher $1 \quad$ Odds Ratio

Study or Subgroup Events Total Events Total Weight M-H, Random, 95\% Cl Year $\begin{array}{lllllllll}\text { Fisher et al. } & 23 & 24 & 0 & 11 & 2.6 \% & 360.33 & {[13.59,9551.34]} & 1980\end{array}$

$\begin{array}{llllllrl}\text { Grosset et al. } & 27 & 53 & 2 & 7 & 8.3 \% & 2.60[0.46,14.59] & 1993\end{array}$

Murayama et al.

$\begin{array}{llll}13 & 47 & 0 & 4\end{array} 3.1 \%$

Dehdashti et al.

Smith et al.

Frontera et al.

Kramer et al.

Rivero-arias et al.

Oliveira et al.

Wilson et al.

Total $(95 \% \mathrm{CI})$

Total events

$10 \quad 31$

0

$\begin{array}{ll}4 & 3.1 \% \\ 9 & 3.2 \%\end{array}$

$3.52[0.18,69.94] 1997$

$9.28[0.49,175.17] 2003$

$5.27[0.26,105.75] 2005$

$2.17[1.34,3.50] 2006$

$\begin{array}{lllll}339 & 917 & 23 & 108 & 39.6 \%\end{array}$

$\begin{array}{rrrrr}339 & 917 & 23 & 108 & 39.6 \% \\ 53 & 151 & 0 & 6 & 3.3 \%\end{array}$

$7.06[0.39,127.77] 2009$

$3.03[1.58,5.79] 2009$

$1.36[0.04,46.65] 2011$

$4.54[0.25,81.09] 2012$

Heterogeneity: $\mathrm{Tau}^{2}=0.13 ; \mathrm{Chi}^{2}=11.32, \mathrm{df}=9(\mathrm{P}=0.25) ; \mathbf{I}^{2}=20 \%$

Test for overall effect: $Z=4.25(P<0.0001)$

$3.21[1.87,5.49]$

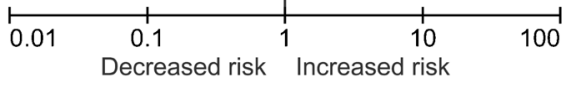

C

Fisher $4 \quad$ Fisher 1

Odds Ratio

Odds Ratio

Study or Subgroup Events Total Events Total Weight M-H, Random, 95\% Cl Year

\begin{tabular}{|c|c|c|c|c|c|}
\hline Fisher et al. & 0 & 5 & 0 & 11 & \\
\hline Grosset et al. & 6 & 28 & 2 & 7 & $4.4 \%$ \\
\hline Murayama et al. & 2 & 6 & 0 & 4 & $1.4 \%$ \\
\hline Dehdashti et al. & 9 & 34 & 0 & 9 & $1.8 \%$ \\
\hline Smith et al. & 13 & 69 & 0 & 6 & $1.8 \%$ \\
\hline Frontera et al. & 55 & 176 & 23 & 108 & $49.5 \%$ \\
\hline Rivero-arias et al. & 166 & 578 & 11 & 101 & $36.6 \%$ \\
\hline Kramer et al. & 6 & 50 & 0 & 6 & $1.7 \%$ \\
\hline Oliveira et al. & 7 & 11 & 0 & 1 & $1.3 \%$ \\
\hline Wilson et al. & 1 & 16 & 0 & 7 & $1.4 \%$ \\
\hline Total $(95 \% \mathrm{Cl})$ & \multicolumn{3}{|c|}{973} & 260 & $100.0 \%$ \\
\hline Total events & 265 & & 36 & & \\
\hline \multicolumn{6}{|c|}{$\begin{array}{l}\text { Heterogeneity: } \text { Tau }^{2}=0.00 ; \mathrm{Chi}^{2}=5.14, \mathrm{df}=8(P=0.74) ; \mathrm{I}^{2}=0 \% \\
\text { Test for overall effect: } Z=3.94(P<0.0001)\end{array}$} \\
\hline
\end{tabular}

Not estimable 1980
$0.68[0.10,4.43] 1993$ $5.00[0.18,136.32] 1997$

$7.08[0.37,133.86] 2003$

$3.11[0.16,58.59] 2005$

$1.68[0.96,2.94] 2006$

$3.30[1.72,6.32] 2009$

$1.90[0.10,37.83] 2009$

$5.00[0.17,150.92] 2011$

$1.45[0.05,40.04] 2012$

$2.21[1.49,3.28]$

Test for overall effect: $Z=3.94(P<0.0001)$

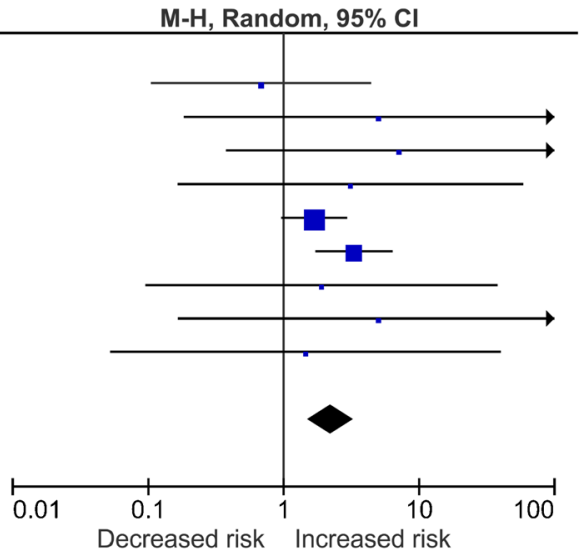

Fig. 2 a Forest plot comparing risk of DCI of Fisher 2 with Fisher 1 patients. b Forest plot comparing risk of DCI of Fisher 3 with Fisher 1 patients. c Forest plot comparing risk of DCI of Fisher 4 with Fisher 1 patients

Fisher 4. For the modified Fisher and Hijdra sum score, no pooled ORs per individual grade could be calculated. Fisher grades were significantly associated with DCI in less studies compared to the other radiological grades. The results of this review should be interpreted with care as the risk of bias was high in the included studies.
To our knowledge, this is the first systematic review assessing the association of radiological scales for grading SAH with DCI. One narrative review reported an overview of all available radiological scales for predicting vasospasm until 2006; however, no associations with DCI were presented in this review [6]. A recent systematic review assessed all risk 
Table 2 Pooled odds ratios for development of delayed cerebral ischemia

\begin{tabular}{llll}
\hline & Fisher 1 & Fisher 2 & Fisher 3 \\
\hline Fisher 1 & Reference & & \\
Fisher 2 & $1.53(1.01-2.32)$ & Reference & \\
Fisher 3 & $3.21(1.87-5.49)$ & $2.10(1.40-3.15)$ & Reference \\
Fisher 4 & $2.21(1.49-3.28)$ & $1.38(0.93-2.05)$ & $0.60(0.37-0.97)$ \\
\hline
\end{tabular}

factors for DCI showing that smoking is an established predictor of DCI; however, the radiological scales were not assessed in this review [49].

Fisher et al. showed that patients with Fisher 3 had the highest risk of vasospasm, a well-known cause of DCI [7]. Our review showed that patients with Fisher 3 also have the highest risk of clinical DCI (OR 3.2). The pooled analysis further showed that patients with Fisher 4 have a significantly lower risk of DCI compared to Fisher 3 patients. The main difference between Fisher 3 and Fisher 4 is the presence of blood outside the subarachnoid space in Fisher 4 with extension to the ventricles (IVH) or parenchyma (IPH). The thickness of SAH does not play a role in the scale difference. Habitually, most Fisher 4 patients will have a larger quantity of SAH and part of this blood is "escaping" to the ventricular system. However, even in patients with a perimesencephalic hemorrhage, blood can migrate into the 4th ventricle, upgrading these patients with a low tendency to develop DCI to a Fisher grade 4. This might explain the lower rate of DCI in Fisher grade 4 versus grade 3 patients. Furthermore, due to the presence of an IPH, Fisher 4 patients may be in poorer clinical condition which masks clinical deterioration [66]. The Fisher scale lacks a separate grade for patients with both thick SAH and IVH, which the modified Fisher does have. As such, patients with both thick SAH and IVH cannot be categorized in a Fisher grade.

In our sensitivity analysis, we analyzed if the strength of the association between the Fisher scale and DCI is dependent on the definition of DCI. The OR for DCI in Fisher 3 patients was higher in studies that used clinical deterioration and angiographic vasospasm to diagnose DCI, compared to those using clinical signs only. However, this high OR may be largely due to the inclusion of the results from the original paper by Fisher et al., in which patients were included with angiographic vasospasm as part of the definition of DCI. In this study all patients that developed DCI were graded as Fisher 3 [7]. Furthermore, confidence intervals were broad so no firm conclusions can be drawn based on this data.

We could not collect sufficient comparable data to calculate pooled ORs per grade of the modified Fisher scale and Hijdra sum score. We believe there are several reasons for this. There were a considerably lower number of studies using these scales. Even after the introduction of the modified Fisher in 2006, the Fisher scale was the most frequently used scale in the studies included in this review. As this was also the case for studies published in the last 5 years, this is not only due to later introduction of the scale. The Hijdra sum score may be too extensive and cumbersome for widespread usage, as this score requires grading of the amount of blood in ten basal cisterns and four ventricles separately. Another reason for not pooling the data is the large variability in data reporting. The usage of a wide range of definitions for DCI resulted in the exclusion of many studies that did not use a clinical definition of DCI. Furthermore, various categories of radiological grades were frequently grouped together, and a variety of effect estimates was used.

One of the most important strengths of this review is the presentation of the first formal meta-analysis on the association of the Fisher scale with DCI. The usage of clinical DCI as end point resulted in more homogeneous outcome data. The use of clinical DCI as endpoint is also a limitation of this study. This diagnosis may be more subjective and have a higher interobserver variation compared to radiological DCI. Furthermore, clinical DCI cannot be diagnosed in comatose patients. However, as follow-up imaging is frequently not routinely made, the clinical relevance of radiological DCI remains questionable. Finally, as not for all studies the risk of publication bias could be evaluated by a funnel plot, a publication bias may have occurred.

This review shows several advantages of the modified Fisher scale over the Fisher scale for clinical practice. Firstly, even though no pooled OR could be calculated, modified Fisher 4 patients had the highest rate of DCI. This may show that this scale identifies the group which has the highest risk of DCI. Secondly, the modified Fisher scale shows an increasing risk of DCI per grade increase on the scale, whereas the Fisher scale does not. This is counter-intuitive for a scale that is developed to predict DCI and makes the scale less suitable for clinical practice. Thirdly, the Fisher scale was in just over half of the included studies significantly associated with DCI. This may show the limited ability of the Fisher scale to differentiate between patients with a high and a low risk of DCI. In contrast, the other scales were more frequently associated with DCI. For the Hijdra sums score, not enough comparable data could be collected. Thus, the possibility that the Hijdra score has a higher association to DCI as the Fisher and modified Fisher score cannot be ruled out. Recently, new radiological scales like the Barrow Neurological Institute SAH Grading Scale, incorporation of the Modified Graeb score to the modified Fisher, and quantification of SAH volume have been introduced [67, 68-71]. These scales measure the amount of blood in a more quantitative manner and have shown high associations with DCI and reduced interobserver variability. 


\section{Conclusion}

This review shows that the Fisher scale, modified Fisher scale, and Hijdra sum score are all associated with clinical DCI. The risk of DCI, however, does not increase with increasing Fisher scale as opposed to the other grading scales. Furthermore, the modified Fisher scale was more commonly significantly associated with clinical DCI than the Fisher scale, which may advocate the use of the modified Fisher in future SAHrelated studies.

Acknowledgements We thank J Daams of the AMC Medical Library for his contribution to the literature search.

\section{Compliance with ethical standards}

Funding This study was funded by NutsOhra Grant number 1403-023.

Competing interests The authors declare that they have no conflict of interest.

Ethical approval This article does not contain any studies with human participants performed by any of the authors.

Informed consent Statement of informed consent was not applicable since the authors did not collect any patient data.

Open Access This article is distributed under the terms of the Creative Commons Attribution 4.0 International License (http:// creativecommons.org/licenses/by/4.0/), which permits unrestricted use, distribution, and reproduction in any medium, provided you give appropriate credit to the original author(s) and the source, provide a link to the Creative Commons license, and indicate if changes were made.

Publisher's note Springer Nature remains neutral with regard to jurisdictional claims in published maps and institutional affiliations.

\section{References}

1. Roos YB, de Haan RJ, Beenen LF et al (2000) Complications and outcome in patients with aneurysmal subarachnoid haemorrhage: a prospective hospital based cohort study in the Netherlands. J Neurol Neurosurg Psychiatry 68:337-341

2. van Gijn J, Kerr RS, Rinkel GJ (2007) Subarachnoid haemorrhage. Lancet 369:306-318

3. Nomura Y, Kawaguchi M, Yoshitani K, Kurita N, Hayashi H, Tamura K, Motoyama Y, Nakase H, Furuya H (2010) Retrospective analysis of predictors of cerebral vasospasm after ruptured cerebral aneurysm surgery: influence of the location of subarachnoid blood. J Anesth 24:1-6

4. Hijdra A, van Gijn J, Nagelkerke NJ, Vermeulen M, van Crevel H (1988) Prediction of delayed cerebral ischemia, rebleeding, and outcome after aneurysmal subarachnoid hemorrhage. Stroke 19: $1250-1256$

5. Brouwers PJ, Dippel DW, Vermeulen M, Lindsay KW, Hasan D, van Gijn J (1993) Amount of blood on computed tomography as an independent predictor after aneurysm rupture. Stroke 24:809-814
6. Klimo P, Schmidt RH (2006) Computed tomography grading schemes used to predict cerebral vasospasm after aneurysmal subarachnoid hemorrhage: a historical review. Neurosurg Focus 21:E5

7. Fisher CM, Kistler JP, Davis JM (1980) Relation of cerebral vasospasm to subarachnoid hemorrhage visualized by computerized tomographic scanning. Neurosurgery 6:1-9

8. Claassen J, Bernardini GL, Kreiter K, Bates J, du YE, Copeland D, Connolly ES, Mayer SA (2001) Effect of cisternal and ventricular blood on risk of delayed cerebral ischemia after subarachnoid hemorrhage: the Fisher scale revisited. Stroke 32:2012-2020

9. Frontera JA, Claassen J, Schmidt JM, Wartenberg KE, Temes R, Connolly ES, Macdonald RL, Mayer SA (2006) Prediction of symptomatic vasospasm after subarachnoid hemorrhage: the modified fisher scale. Neurosurgery 59:21-27

10. Kramer AH, Hehir M, Nathan B et al (2008) A comparison of 3 radiographic scales for the prediction of delayed ischemia and prognosis following subarachnoid hemorrhage. J Neurosurg 109:199207

11. Vergouwen MD, Vermeulen M, van Gijn J et al (2010) Definition of delayed cerebral ischemia after aneurysmal subarachnoid hemorrhage as an outcome event in clinical trials and observational studies proposal of a multidisciplinary research group. Stroke 41:23912395

12. Macdonald RL (2013) Delayed neurological deterioration after subarachnoid haemorrhage. Nat Rev Neurol 10:44-58

13. Moher D, Liberati A, Tetzlaff J, Altman DG, for the PRISMA Group (2009) Preferred reporting items for systematic reviews and meta-analyses: the PRISMA statement. BMJ 339:b2535

14. Ryan R. Cochrane consumers and communication review group. Heterogeneity and subgroup analyses in Cochrane consumers and communication review group reviews: planning the analysis at protocol stage. http://cccrg.cochrane.org, December 2016. Accessed August 18th, 2017

15. Allen G, Ahn H, Preziosi T, Battye R, Boone S, Chou S (1983) Cerebral arterial spasm - a controlled trial of nimodipine in patients with subarachnoid hemorrhage. N Engl J Med 308:619-624

16. Adams H, Kassell N, Torner J, Haley E (1987) Predicting cerebral ischemia after aneurysmal subarachnoid hemorrhage: influences of clinical condition, CT results, and antifibrinolytic therapy. A report of the cooperative aneurysm study. Neurology 37:1586-1591

17. Grosset DG, McDonald I, Cockburn M, Straiton J, Bullock RR (1994) Prediction of delayed neurological deficit after subarachnoid haemorrhage: a CT blood load and Doppler velocity approach. Neuroradiology 36:418-421

18. Rabb CH, Tang G, Chin LS, Giannotta SL (1994) A statistical analysis of factors related to symptomatic cerebral vasospasm. Acta Neurochir (Wien) 127:27-31

19. Lasner TM, Weil RJ, Riina HA, King JT, Zager EL, Raps EC et al (1997) Cigarette smoking-induced increase in the risk of symptomatic vasospasm after aneurysmal subarachnoid hemorrhage. $\mathrm{J}$ Neurosurg 87:381-384

20. Murayama Y, Malisch T, Guglielmi G, Mawad ME, Viñuela F, Duckwiler GR et al (1997) Incidence of cerebral vasospasm after endovascular treatment of acutely ruptured aneurysms: report on 69 cases. J Neurosurg 87:830-835

21. Charpentier C, Audibert G, Guillemin F, Civit T, Ducrocq X, Bracard S et al (1999) Multivariate analysis of predictors of cerebral vasospasm occurrence after aneurysmal subarachnoid hemorrhage. Stroke 30:1402-1408

22. Juvela S (2000) Plasma endothelin concentrations after aneurysmal subarachnoid hemorrhage. J Neurosurg 92:390-400

23. Juvela S (2000) Plasma endothelin concentrations after aneurysmal subarachnoid hemorrhage. J Neurosurg 92:390-400

24. McGirt MJ, Mavropoulos JC, McGirt LY, Alexander MJ, Friedman $\mathrm{AH}$, Laskowitz DT et al (2003) Leukocytosis as an independent risk 
factor for cerebral vasospasm following aneurysmal subarachnoid hemorrhage. J Neurosurg 98:1222-1226

25. Dehdashti AR, Mermillod B, Rufenacht DA, Reverdin A, De Tribolet N (2004) Does treatment modality of intracranial ruptured aneurysms influence the incidence of cerebral vasospasm and clinical outcome? Cerebrovasc Dis 17:53-60

26. Klimo PJ, Kestle JRW, MacDonald JD, Schmidt RH (2004) Marked reduction of cerebral vasospasm with lumbar drainage of cerebrospinal fluid after subarachnoid hemorrhage. J Neurosurg 100:215-224

27. Singhal A, Topcuoglu M, Dorer DJ, Ogilvy CS, Carter BS, Koroshetz WJ (2005) SSRI and statin use increases the risk for vasospasm after subarachnoid hemorrhage. Neurology 64:10081013

28. Reilly C, Amidei C, Tolentino J, Jahromi BS, Macdonald RL (2004) Clot volume and clearance rate as independent predictors of vasospasm after aneurysmal subarachnoid hemorrhage. J Neurosurg 101:255-261

29. Hoh BL, Topcuoglu MA, Singhal AB, Pryor JC, Rabinov JD, Rordorf GA et al (2004) Effect of clipping, craniotomy, or intravascular coiling on cerebral vasospasm and patient outcome after aneurysmal subarachnoid hemorrhage. Neurosurgery 55:779-789

30. Hirashima Y, Hamada H, Kurimoto M, Origasa H, Endo S (2005) Decrease in platelet count as an independent risk factor for symptomatic vasospasm following aneurysmal subarachnoid hemorrhage. J Neurosurg 102:882-887

31. Smith ML, Abrahams JM, Chandela S, Smith MJ, Hurst RW, Le Roux PD (2005) Subarachnoid hemorrhage on computed tomography scanning and the development of cerebral vasospasm: the fisher grade revisited. Surg Neurol 63:229-234

32. Oertel M, Schumacher U, McArthur DL, Kästner S, Böker DK (2006) S-100B and NSE: markers of initial impact of subarachnoid haemorrhage and their relation to vasospasm and outcome. J Clin Neurosci 13:834-840

33. McGirt MJ, Blessing R, Alexander MJ, Nimjee SM, Woodworth GF, Friedman AH et al (2006) Risk of cerebral vasopasm after subarachnoid hemorrhage reduced by statin therapy: a multivariate analysis of an institutional experience. J Neurosurg 105:671-674

34. Oh SY, Kwon JT, Hong HJ, Kim JB, Suk JS (2007) Relationship between leukocytosis and vasospasms following aneurysmal subarachnoid hemorrhage. J Korean Neurosurg Soc 41:153-156

35. Krishnamurthy S, Kelleher J, Lehman E, Cockroft K (2007) Effects of tobacco dose and length of exposure on delayed neurological deterioration and overall clinical outcome after aneurysmal subarachnoid hemorrhage. Neurosurgery 61:475-481

36. Gonzalez NR, Boscardin WJ, Glenn T, Vinuela F, Martin NA (2007) Vasospasm probability index: a combination of transcranial doppler velocities, cerebral blood flow, and clinical risk factors to predict cerebral vasospasm after aneurysmal subarachnoid hemorrhage. J Neurosurg 107:1101-1112

37. Dhar R, Diringer MN (2008) The burden of the systemic inflammatory response predicts vasospasm and outcome after subarachnoid hemorrhage. Neurocrit Care 2008:404-412

38. Starke RM, Kim GH, Komotar RJ, Hickman ZL, Black EM, Rosales MB et al (2008) Endothelial nitric oxide synthase gene single-nucleotide polymorphism predicts cerebral vasospasm after aneurysmal subarachnoid hemorrhage. J Cereb Blood Flow Metab 28:1204-1211

39. Kramer AH, Hehir M, Nathan B, Gress D, Dumont AS, Kassell NF et al (2008) A comparison of 3 radiographic scales for the prediction of delayed ischemia and prognosis following subarachnoid hemorrhage. J Neurosurg 109:199-207

40. Rivero-Arias O, Wolstenholme J, Gray A, Molyneux AJ, Kerr RSC, Yarnold JA et al (2009) The costs and prognostic characteristics of ischaemic neurological deficit due to subarachnoid haemorrhage in the United Kingdom : evidence from the MRC International Subarachnoid Aneurysm Trial. J Neurol 256:364-373

41. Dumont T, Rughani A, Silver J, Tranmer BI (2009) Diabetes mellitus increases risk of vasospasm following aneurysmal subarachnoid hemorrhage independent of glycemic control. Neurocrit Care 11:183-189

42. Kramer AH, Mikolaenko I, Deis N, Dumont AS, Kassell NF, Bleck $\mathrm{TP}$ et al (2010) Intraventricular hemorrhage volume predicts poor outcomes but not delayed ischemic neurological deficits among patients with ruptured cerebral aneurysms. Neurosurgery 67: 1044-1052

43. Kasius KM, Frijns CJM, Algra A, Rinkel GJE (2010) Association of platelet and leukocyte counts with delayed cerebral ischemia in aneurysmal subarachnoid hemorrhage. Cerebrovasc Dis 29:576583

44. Yousef K, Crago E, Kuo CW, Horowitz M, Hravnak M (2010) Predictors of delayed cerebral ischemia after aneurysmal subarachnoid hemorrhage: a cardiac focus. Neurocrit Care 13:366-372

45. Oliveira AMP, Paiva WS, de Figueiredo EG, Oliveira HA, Teixeira MJ (2011) Fisher revised scale for assessment of prognosis in patients with subarachnoid hemorrhage. Arq Neuropsiquiatr 69:910 913

46. Ibrahim GM, Vachhrajani S, Ilodigwe D, Kassell NF, Mayer SA, Ruefenacht D et al (2012) Method of aneurysm treatment does not affect clot clearance after aneurysmal subarachnoid hemorrhage. Neurosurgery 70:102-109

47. Al-Tamimi YZ, Bhargava D, Feltbower RG, Hall G, Goddard AJP, Quinn AC et al (2012) Lumbar drainage of cerebrospinal fluid after aneurysmal subarachnoid hemorrhage: a prospective, randomized, controlled trial (LUMAS). Stroke 43:677-682

48. Zhu XD, Chen JS, Zhou F, Liu QC, Chen G, Zhang JM (2012) Relationship between plasma high mobility group box-1 protein levels and clinical outcomes of aneurysmal subarachnoid hemorrhage. J Neuroinflammation 9:194

49. de Rooij NK, Rinkel GJ, Dankbaar JW et al (2013) Delayed cerebral ischemia after subarachnoid hemorrhage: a systematic review of clinical, laboratory, and radiological predictors. Stroke 44:43-54

50. Ohnishi H, Iihara K, Kaku Y, Yamauchi K, Fukuda K, Nishimura K et al (2013) Haptoglobin phenotype predicts cerebral vasospasm and clinical deterioration after aneurysmal subarachnoid hemorrhage. J Stroke Cerebrovasc Dis 22:520-526

51. Karamchandani RR, Fletcher JJ, Pandey AS, Rajajee V (2014) Incidence of delayed seizures, delayed cerebral ischemia and poor outcome with the use of levetiracetam versus phenytoin after aneurysmal subarachnoid hemorrhage. J Clin Neurosci 21:1507-1513

52. Romero FR, Cataneo DC, Cataneo AJM (2014) C-reactive protein and vasospasm after aneurysmal subarachnoid hemorrhage1. Acta Cir Bras 29:340-345

53. Yousef KM, Balzer JR, Crago EA, Poloyac SM, Sherwood PR (2014) Transcranial regional cerebral oxygen desaturation predicts delayed cerebral ischaemia and poor outcomes after subarachnoid haemorrhage: a correlational study. Intensive Crit care Nurs 30: 346-352

54. de Oliveira Manoel AL, Jaja BN, Germans MR, Yan H, Qian W, Kouzmina E, et al: The VASOGRADE: a simple grading scale for prediction of delayed cerebral ischemia after subarachnoid hemorrhage. Stroke 46:1826-1831, 2015

55. Calviere L, Nasr N, Arnaud C, Czosnyka M, Viguier A, Tissot B et al (2015) Prediction of delayed cerebral ischemia after subarachnoid hemorrhage using cerebral blood flow velocities and cerebral autoregulation assessment. Neurocrit Care 23:253-258

56. Dhandapani S, Aggarwal A, Srinivasan A, Meena R, Gaudihalli S, Singh $\mathrm{H}$ et al (2015) Serum lipid profile spectrum and delayed cerebral ischemia following subarachnoid hemorrhage: Is there a relation? Surg Neurol Int 6:S543-S548 
57. Rodriguez-Régent C, Hafsa M, Turc G, Ben Hassen W, Edjlali M, Sermet A et al (2016) Early quantitative CT perfusion parameters variation for prediction of delayed cerebral ischemia following aneurysmal subarachnoid hemorrhage. Eur Radiol 26:2956-2963

58. Malinova V, Schatlo B, Voit M, Suntheim P, Rohde V, Mielke D (2016) Identification of specific age groups with a high risk for developing cerebral vasospasm after aneurysmal subarachnoid hemorrhage. Neurosurg Rev 39:429-436

59. Kozak N, Bereczki D, Szabo S (2016) Predictors of symptomatic vasospasm after subarachnoid hemorrhage: a single center study of 457 consecutive cases. Turk Neurosurg 26:545-549

60. Behrouz R, Birnbaum L, Grandhi R, Johnson J, Misra V, Palacio S et al (2016) Cannabis use and outcomes in patients with aneurysmal subarachnoid hemorrhage. Stroke 47:1371-1373

61. Mijiti M, Mijiti P, Axier A, Amuti M, Guohua Z, Xiaojiang C et al (2016) Incidence and predictors of angiographic vasospasm, symptomatic vasospasm and cerebral infarction in chinese patients with aneurysmal subarachnoid hemorrhage. PLoS One 11:1-12

62. Aldakkan A, Mansouri A, Jaja BNR, Alotaibi NM, Macdonald RL, Noble A et al (2017) Predictors of delayed cerebral ischemia in patients with aneurysmal subarachnoid hemorrhage with asymptomatic angiographic vasospasm on admission. World Neurosurg 97:199-204

63. Oda S, Shimoda M, Hirayama A, Imai M, Komatsu F, Shigematsu $\mathrm{H}$ et al (2018) Retrospective review of previous minor leak before major subarachnoid hemorrhage diagnosed by MRI as a predictor of occurrence of symptomatic delayed cerebral ischemia. J Neurosurg 128:499-505

64. Griessenauer CJ, Starke RM, Foreman PM, Hendrix P, Harrigan MR, Fisher WS et al (2018) Associations between endothelin polymorphisms and aneurysmal subarachnoid hemorrhage, clinical vasospasm, delayed cerebral ischemia, and functional outcome. J Neurosurg 128:499-505
65. Rostami E, Engquist H, Howells T, Johnson U, Ronne-Engström E, Nilsson P et al (2018) Early low cerebral blood flow and high cerebral lactate: prediction of delayed cerebral ischemia in subarachnoid hemorrhage. J Neurosurg 128:1762-1770

66. Wan A, Jaja BN, Schweizer TA et al (2016) Clinical characteristics and outcome of aneurysmal subarachnoid hemorrhage with intracerebral hematoma. J Neurosurg 125:1344-1351

67. Wilson DA, Nakaji P, Abla AA, Uschold TD, Fusco DJ, Oppenlander ME, Albuquerque FC, McDougall CG, Zabramski JM, Spetzler RF (2012) A simple and quantitative method to predict symptomatic vasospasm after subarachnoid hemorrhage based on computed tomography: beyond the fisher scale. Neurosurgery 71:869-875

68. Zijlstra IA, Gathier CS, Boers AM, Marquering HA, Slooter AJ, Velthuis BK, Coert BA, Verbaan D, van den Berg R, Rinkel GJ, Majoie CB (2016) Association of automatically quantified blood volume after aneurysmal subarachnoid hemorrhage with delayed cerebral ischemia. AJNR Am J Neuroradiol 37:1588-1593

69. Eagles ME, Jaja BNR, Macdonald RL (2018) Incorporating a modified graeb score to the modified fisher scale for improved risk prediction of delayed cerebral ischemia following aneurysmal subarachnoid hemorrhage. Neurosurgery 82:299-305

70. Boers AM, Zijlstra IA, Gathier CS, van den Berg R, Slump CH, Marquering HA, Majoie CB (2014) Automatic quantification after subarachnoid hemorrhage on non-contrast computed tomography. AJNR Am J Neuroradiol 35:2279-2286

71. Dengler NF, Diesing D, Sarrafzadeh A, Wolf S, Vajkoczy P (2017) The Barrow neurological institute scale revisited: predictive capabilities for cerebral infarction and clinical outcome in patients with aneurysmal subarachnoid hemorrhage. Neurosurgery 81:341-349. https://doi.org/10.1093/neuros/nyw141 Published Online First: 14 February 2017 